\title{
In memory of Anders Wikström (1937-2015)
}

Anders Wikström was born in 1937. He studied at Uppsala University, in Sweden, graduating in Mathematics, Chemistry and Geology in 1961 and obtaining his Doctoral degree in 1968 in Mineralogy and Petrology with a thesis dealing with retrograde reactions in eclogites. Between 1968 and 2000, when he retired, Anders was employed as state geologist and then senior state geologist at the Geological Survey of Sweden. He was very active in the study of granites and metamorphic rocks from Sweden. In 2012 he contacted the IUGS Heritage Stone Task Group with the purpose of bringing greater attention to historically important natural stones that had been used in construction for centuries in from Sweden, notably Kolmården stone and Swedish porphyries. Published information on these was largely in Swedish so he authored two papers on this subject in English to bring these to the attention of the wider scientific community and general public. This led to museums in Sweden and from Russia to seek copies of the papers and

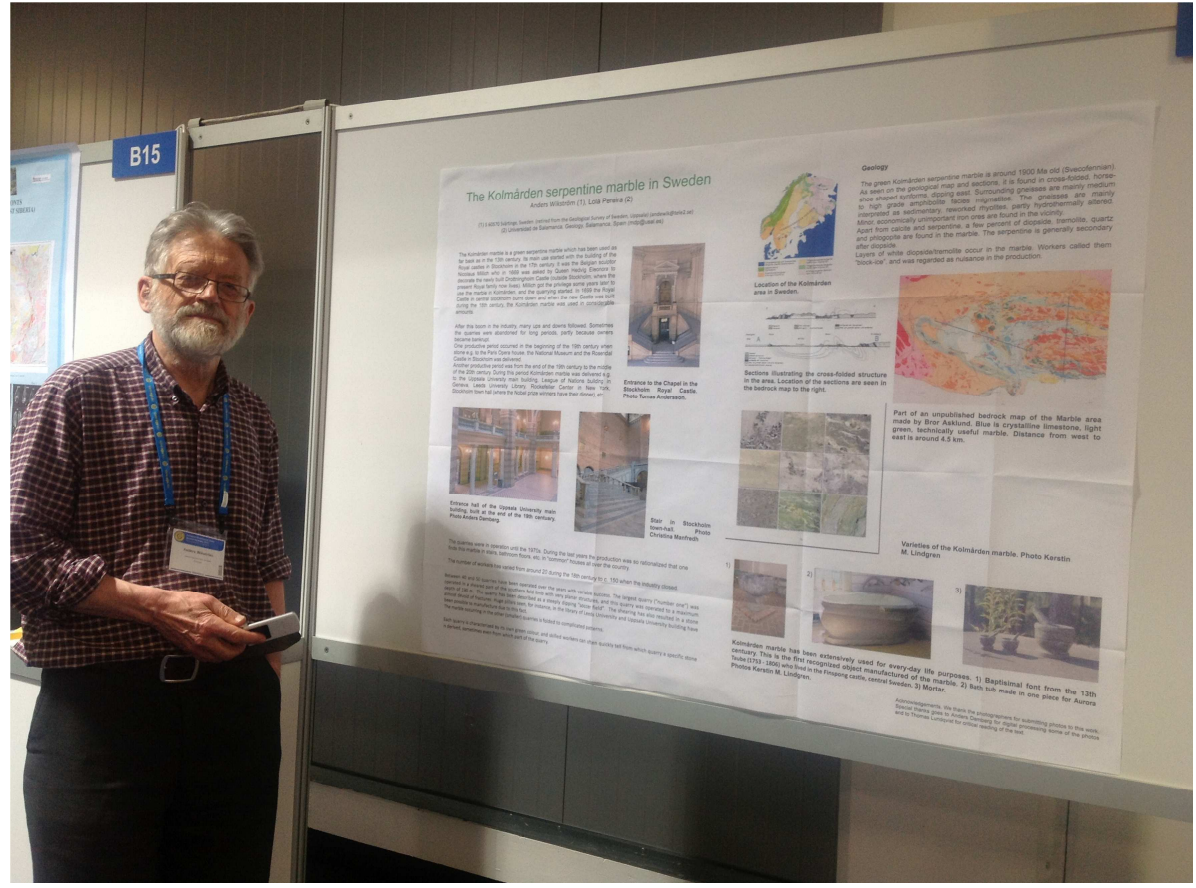

Anders Wikström presenting his poster on the Kolmården serpentine marble. EGU 2013. Photo by Lola Pereira. to arrange talks at Stockholm and Uppsala.

Anders was passionate about music (he played tenor saxophone and enjoyed the Christmas season by playing with local bands in supermarkets), he loved animals, especially his dogs and cats, and sailing until he had to sell his boat after 45 years of use. He remained very active in writing on and discussing science until he was diagnosed with Amyotrophic Lateral Sclerosis in the Summer of 2015. On the $8^{\text {th }}$ of November he passed away. He leaves wife, children and grandchildren, who receive our sincere condolences. We, in IUGS, have lost a valued colleague and a very dear friend. 